\title{
Improved rainfall estimation over the Indian monsoon region by synergistic use of Kalpana-1 and rain gauge data
}

\author{
R. M. GAIROLA \\ Atmospheric and Oceanic Sciences Group, Space Applications Centre, Indian Space Research Organisation, \\ Ahmedabad, India - 380015
}

SATYA PRAKASH

Atmospheric and Oceanic Sciences Group, Space Applications Centre, Indian Space Research Organisation, Ahmedabad, India - 380 015; National Centre for Medium Range Weather Forecasting, Earth System Science Organization, Ministry of Earth Sciences, A-50, Sector-62, Noida, India - 201309

Corresponding author; e-mail: spsharma_01@yahoo.co.in

\author{
P. K. PAL \\ Atmospheric and Oceanic Sciences Group, Space Applications Centre, Indian Space Research Organisation, \\ Ahmedabad, India - 380015
}

Received June 25, 2013; accepted October 31, 2014

\begin{abstract}
RESUMEN
En este trabajo se busca calcular la precipitación en la región del monzón de la India mediante el uso sinérgico de datos pluviométricos y del algoritmo multiespectral de precipitación del Sistema Nacional de Satélites de la India (IMSRA, por sus siglas en inglés), obtenido mediante el satélite geostacionario Kalpana-1, utilizando un método de rectificación progresivo para corregir las estimaciones de precipitación de IMSRA. El método de rectificación progresiva se beneficia de las altas resoluciones espaciales y temporales del satélite Kalpana-1, así como de estimaciones pluviométricas precisas. Se realiza un análisis preliminar para la temporada 2010 del monzón del suroeste en una escala diaria. El método de rectificación progresiva se aplica a una resolución de $1^{\circ} \times 1^{\circ}$ determinada por el análisis de autocorrelación espacial. Los resultados se comparan con cuatro productos multisatelitales independientes de precipitación global: el mapeo satelital global de precipitación; productos de monitoreo de precipitación en tiempo casi real y para investigación del análisis multisatelital de precipitación de la Misión de Medición de Lluvias Tropicales, y el producto del Proyecto Global sobre la Climatología de las Precipitaciones. El análisis objetivo de las estimaciones de precipitación muestra una notable mejoría respecto de las estimaciones basadas sólo en mediciones satelitales en el sur de la India. La comparación con observaciones pluviométricas independientes también muestra una considerable mejoría en términos de correlación, sesgo y error cuadrático medio, especialmente en regiones con buena densidad de mediciones de precipitación. Los resultados globales demuestran que el uso sinérgico de mediciones satelitales e in situ tiene el potencial de facilitar estimaciones de precipitación más exactas en la región del monzón de la India.
\end{abstract}

\begin{abstract}
In this paper, an attempt has been made to estimate rainfall over the Indian monsoon region by the synergistic use of the geostationary Kalpana-1 satellite-derived INSAT Multispectral Rainfall Algorithm (IMSRA) rainfall estimates and rain gauge data, using a successive correction method in order to further refine the operational IMSRA rainfall estimates. The successive correction method benefits from high spatial and temporal resolutions of the Kalpana-1 satellite and accurate rainfall estimates from rain gauges. A preliminary analysis is done for the southwest monsoon season of 2010 at a daily scale. The successive correction method is applied
\end{abstract}


at a $1^{\circ}$ latitude $\times 1^{\circ}$ longitude resolution determined by the spatial autocorrelation analysis. Results are compared with four independent global multisatellite rainfall products, namely the Global Satellite Mapping of Precipitation, the Tropical Rainfall Measuring Mission Multisatellite Precipitation Analysis near-real time and research version rainfall monitoring products, and the Global Precipitation Climatology Project rainfall product. The objectively analyzed rainfall estimates show noticeable improvement over the satellite-based rainfall estimates alone over southern India. Comparison with independent rain gauge observations shows a considerable improvement in terms of correlation, bias and root-mean-square error after objective analysis, especially over the regions where density of rain gauge is fairly good. Overall results reveal that the synergistic use of satellite and in situ observations has potential for more accurate rainfall estimations over the Indian monsoon region.

Keywords: Indian monsoon region, INSAT Multispectral Rainfall Algorithm, rain gauge, objective analysis.

\section{Introduction}

Accurate estimation of rainfall over India, especially during the southwest monsoon season, is very important for agricultural production, which has a large social and economic impact. Though conventional rain gauges and weather radars essentially provide accurate measurements of rainfall, their heterogeneous distribution over unpopulated regions like mountainous areas, deserts and over large oceanic regions limits its use for global and regional scale applications. On the other hand, satellite-based rainfall retrieval provides homogeneous spatial and temporal distributions of rainfall, which is a valuable source of information for flood forecasting, agriculture and water resource management, numerical weather prediction, moisture budget calculations and numerous other applications in the hydro-meteorological sciences; however, rainfall is one of the most highly varying atmospheric parameters in both space and time.

Following the launch of the first dedicated Indian meteorological geostationary satellite, Kalpana-1, by the Indian Space Research Organisation (ISRO) on September12, 2002 (Kaila et al., 2002), two of the rainfall products have so far become operational at the India Meteorological Department (IMD) and ISRO for rainfall monitoring over the Indian monsoon region. The first product is based on the state-ofthe-art Geostationary Observational Environmental Satellite (GOES) Precipitation Index (GPI) (Arkin and Meisner, 1987), which uses the thermal infrared (TIR) channel of Kalpana-1 for rainfall estimation at a $1^{\circ}$ latitude $\times 1^{\circ}$ longitude spatial resolution (Gairola et al., 2010a). Prakash et al. (2011) compared the Kalpana-1 derived rainfall product with a multisatellite rainfall product (the Global Precipitation Climatology Project, GPCP) and rainfall data from the rain gauge-based Global Precipitation Climatology
Center (GPCC) for the southwest monsoon season of 2009 at various temporal scales (weekly, monthly and seasonally). These authors showed that the Kalpana-1 rainfall product picks up active and break spells of the monsoon very well and performs reasonably well for rainfall estimation at larger spatial and temporal scales. However, this rainfall estimation technique is inadequate for small-scale or heavy rainfall estimation, as it is based on a simple threshold technique.

In order to estimate intense rainfall over India, Mishra et al. (2009) developed an algorithm by the combined use of TIR from Kalpana-1 and near-surface rainfall data from the low-Earth orbiting Tropical Rainfall Measuring Mission-Precipitation Radar (TRMM-PR). They compared their results with in situ observations and showed that the new approach was able to retrieve rainfall with reasonable accuracy. Further, a new algorithm, the Indian National Satellite System (INSAT) Multispectral Rainfall Algorithm (IMSRA), was developed which benefits from the high spatial and temporal resolutions of Kalpana-1 and more accurate rainfall data from TRMM-PR (Prakash et al., 2009; Gairola et al., 2010b). This algorithm also uses proper cloud classification schemes from TIR and water vapor channels of Kalpana-1 and the procedure is the same as the one used by Mishra et al. (2010) for rainfall estimation by the Meteosat-First Generation satellite and TRMM-PR datasets. IMSRA is capable of estimating rainfall from Kalpana-1 satellite data at high spatial $\left(0.25^{\circ}\right.$ latitude $\times 0.25^{\circ}$ longitude) and temporal (3-hourly) resolutions. Prakash et al. (2010) investigated the potential of this new algorithm (IMSRA) for the southwest monsoon seasons of 2008 and 2009 at daily and monthly scales using independently developed quasi-global multisatellite rainfall products and rain gauge data. They noticed that IMSRA captures 
all the synoptic features of the monsoon very well. Though this algorithm performs reasonably well over non-orographic regions, it substantially underestimates rainfall over orographic regions like the west coast of India and foothills of the Himalayas. The difficulty for accurate estimation of orographic rainfall from the TIR-based rainfall estimates is a formidable challenge (Adler et al., 2003). Recently, Sen Roy et al. (2012) independently compared this rainfall product with Kalpana-1 GPI and TRMM Multisatellite Precipitation Analysis (TMPA) estimates and showed that IMSRA is closer to the TMPA estimate in terms of areal spread, geometric shape and location of rainfall areas, as compared to the GPI technique, and is capable of short-period rainfall estimation. This algorithm is also operational at the IMD since 2010 and is used for various agricultural and hydro-meteorological applications and verification of numerical model rainfall outputs (Prakash et al., 2012; Das et al., 2013; Mahesh et al., 2014).

As geostationary satellites provide rapid refresh of the weather systems and rain gauges give accurate measurement of rainfall at specific locations, the synergism of rain gauge and satellite-based rainfall data would essentially provide the optimal rainfall estimation. Several studies in the past emphasized the synergism of rain gauge and satellite-based rainfall estimates for more accurate rainfall estimation (Gairola and Krishnamurti, 1992; Adler et al., 2003; Mitra et al., 2003, 2009; Huffman et al., 2007; Roy Bhowmik and Das, 2007; Krishnamurti et al., 2009; Gairola et al., 2012). Roy Bhowmik and Das (2007) used an objective analysis approach for blending rain gauge data with INSAT derived daily rainfall estimates at $1^{\circ}$ latitude $\times 1^{\circ}$ longitude spatial resolution for rainfall estimation over the Indian monsoon region. They showed that the objectively analyzed rainfall estimates were able to realistically reproduce the detailed features of the Indian summer monsoon. Mitra et al. (2009) used this approach for blending rain gauge data with the near-real time TMPA product over India, which resulted in a rainfall product that is operational at the IMD since 2012 for monsoon rainfall monitoring. Adler et al. (2003) and Huffman et al. (2007) also merged the available rain gauge data over land with multisatellite rainfall products for global rainfall estimation; their products are known as GPCP and TMPA, respectively. Recently, Gairola et al. (2012) blended the available rain gauge data with the Kalpana-1 derived IMSRA rainfall using a successive correction method over Gujarat state to study the heavy rainfall episode of monsoon season 2012, showing that objectively analyzed rainfall estimates perform notably better than satellite-based products alone. Hence, the objective analysis approach combines the advantages of excellent spatial coverage from satellite measurements and accurate rainfall estimates from rain gauge data, and has the potential for optimal rainfall estimation.

The aim of the present study is to estimate rainfall over the Indian monsoon region by the synergistic use of Kalpana-1 derived indigenous IMSRA rainfall and rain gauge data in order to further refine the IMSRA rainfall estimates. Results are compared with four independent global multisatellite rainfall products, namely the Global Satellite Mapping of Precipitation (GSMaP), TMPA-3B42 near-real time and research version 7 rainfall monitoring products, and the GPCP rainfall product. A preliminary analysis is done for the southwest monsoon season of 2010 at daily scale. This study will also be helpful in rainfall estimation from the INSAT-3D satellite data along with rain gauge observations. The road map of the study is as follows: section 2 describes the different rainfall products used in the present study; section 3 highlights the methodology used for objective analysis; a qualitative as well as quantitative discussion of the comparison results obtained for different case studies is presented in section 4 , and conclusions are outlined in section 5 .

\section{Data used}

\subsection{Satellite-derived rainfall data}

The Kalpana-1 geostationary satellite carries onboard a very high-resolution radiometer (VHRR) and a data relay transponder (Kaila et al., 2002). The VHRR sensor operates in three wavelength bands, namely visible (VIS, 0.55-0.75 $\mu \mathrm{m}$ ), thermal infrared (TIR, 10.5-12.5 $\mu \mathrm{m})$ and water vapour (WV, 5.7-7.1 $\mu \mathrm{m})$. IMSRA is the combination of the TIR and microwave measurements, which takes the advantages of the accurate precipitation estimates from the microwave-based observations and the relatively high spatial and temporal resolutions from the TIR-based estimates (Prakash et al., 2009; Gairola et al., 2010b). This algorithm is developed for the small-scale precipitation estimation over the Indian region. The relevant Kalpana-1 daily rainfall data used in this study 
are obtained from the website of the Meteorological and Oceanographic Satellite Data Archival Centre at http://www.mosdac.gov.in.

Moreover, four global multisatellite rainfall datasets, viz. GSMaP (Kubota et al., 2007; Aonashi et al., 2009), TMPA-3B42 near-real time and research version 7 (Huffman et al., 2007, 2010), and GPCP rainfall products (Huffman et al., 2001; Adler et al., 2003) are used for comparison purposes. The TMPA is a multisatellite rainfall product derived from geostationary infrared data and microwave observations available at a $0.25^{\circ}$ latitude $\times 0.25^{\circ}$ longitude spatial resolution and at different temporal resolutions (3-hourly, daily, and monthly). The retrospectively processed version 7 products were released in the late 2012, after some major corrections in version 6 products. The changes in the V7 rainfall-monitoring product over the tropical oceans with respect to the previous V6 product were recently investigated by Prakash et al. (2013) and Prakash and Gairola (2014). The TMPA-3B42 V7 product is one of the best available multisatellite products to estimate rainfall over the Indian monsoon region (Prakash et al., 2014). The TMPA-3B42 near-real time and research monitoring V7 daily rainfall data are obtained from the TRMM website at http://disc2.nascom.nasa.gov/tovas/. The GSMaP project is sponsored by the Core Research for Evolutional Science and Technology (CREST) of the Japan Science and Technology Agency (JST) for the production of a high-precision, high-resolution global rainfall map using satellite data. The GSMaP rainfall product is daily available at $0.1^{\circ}$ latitude $\times 0.1^{\circ}$ longitude spatial resolution from the JST website at http://sharaku.eorc.jaxa.jp/GSMaP/. The GPCP data are merged rainfall analyses that incorporate rainfall estimates from low-Earth orbiting microwave data, geostationary infrared satellite data, and available surface rain gauge observations. This rainfall product was developed to provide improved long-record estimates of rainfall over the globe and is a part of the Global Energy and Water Experiment (GEWEX). Daily GPCP version 1.2 rainfall data available at $1^{\circ}$ latitude $\times 1^{\circ}$ longitude spatial resolution (Huffman et al., 2001) are obtained from the project's website at http://precip.gsfc.nasa.gov/.

\subsection{Rain gauge data}

The ISRO designed automatic weather station (AWS) is a very compact, modular, rugged, powerful and low-cost system housed in a portable, self-contained package. Among many other sensors, it has a tipping bucket rain gauge with a magnet and reed switch, unlimited rainfall measuring capacity, and accuracy of less than $1 \mathrm{~mm}$. The AWS transmits its hourly meteorological data in bursts of 68-millisecond duration (at a data rate of $4.8 \mathrm{kbps}$ ), and the INSAT data collection platform is used for data acquisition. The location map of the ISRO AWS in Figure 1 shows that density of rain gauges is not homogeneous over India. There is a fairly good network of rain gauges over the southern and eastern parts of India whereas the number of gauges is very scarce in the northern regions. The relevant quality-controlled rain gauge data are obtained from the ISRO website at http:// www.mosdac.gov.in.

\section{Methodology}

To merge in situ rainfall data from the AWS rain gauges with Kalpana-1 derived IMSRA rainfall estimates, the successive correction method (Cressman, 1959; Thiebaux and Pedder, 1987), which is one of the simplest and state-of-the-art techniques used for objective analysis, is used. It involves the successive modification of satellite rainfall estimates based on observed rain gauge rainfall data. The objective analysis scheme benefits from the relative advantages

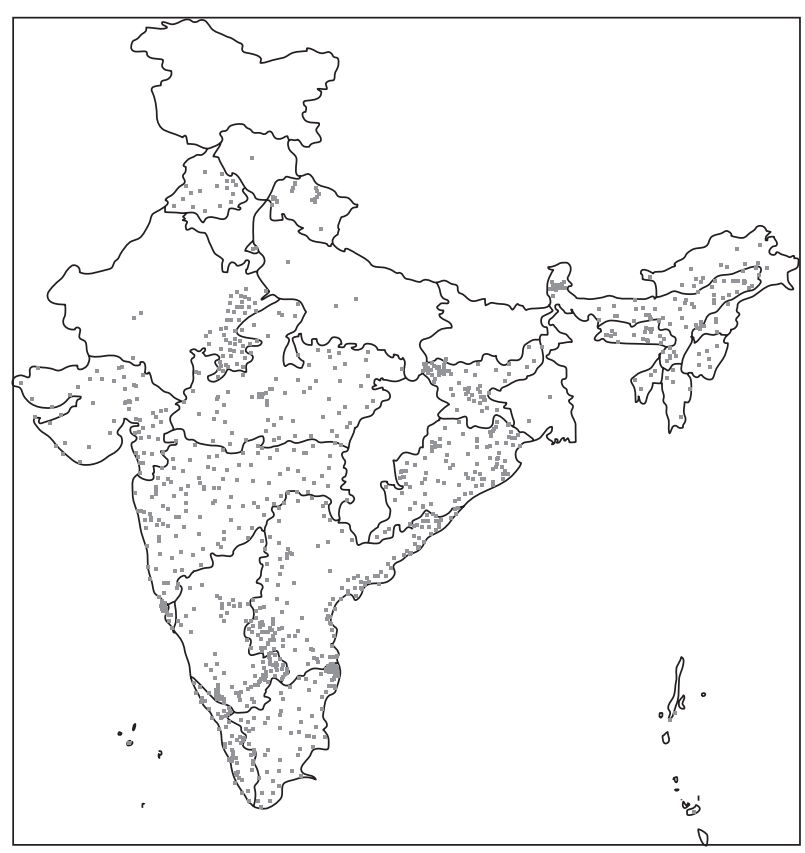

Fig. 1. Location map of ISRO AWS rain gauges over India in 2010. 
of satellite and in situ data. In this method, the background field is corrected by the observed values iteratively during several analysis scans until the correction between the interpolated value and actual observation converges. The interpolated weights are computed using the distance-dependent scheme and the correction $(C)$ is done using the following equation:

$C=\left(\sum W\left(P_{0}-P_{p}\right)\right) / N$

where $P_{o}$ is rainfall at the observation point, $P_{p}$ is the interpolated grid point data at observation point, $N$ is the number of observations, and the weight $(W)$ is given by

$W \begin{cases}=\left(R^{2}-d^{2}\right) /\left(R^{2}+d^{2}\right) & \text { for } d^{2} \leq R^{2} \\ =0 & \text { for } d^{2}>R^{2}\end{cases}$

where $R$ is the radius of rainfall influence and $d$ is the distance of the in situ data point from the grid point. The appropriate radius of rainfall influence is determined by the spatial autocorrelation analysis of daily Kalpana-1 derived IMSRA rainfall data. Roy Bhowmik et al. (2005) used a similar approach for the determination of an appropriate radius of rainfall influence over the Indian monsoon region using gridded rain gauge data at a $1^{\circ}$ latitude $\times 1^{\circ}$ longitude spatial resolution, finding out that it was about $200 \mathrm{~km}$ for objective analysis, although it had day-to-day variations depending on synoptic and geographical conditions. A complete procedure for computing spatial autocorrelation for sea surface salinity in the tropical Indian Ocean was recently discussed by Prakash and Gairola (2013). The spatial autocorrelation analysis is carried out at a daily scale for the southwest monsoon season of 2010 over India using Kalpana-1 derived IMSRA rainfall estimates, as they give homogeneous distribution of rainfall over this region. The averaged result is presented in Figure 2, which depicts a decorrelation distance (where autocorrelation drops to $1 / \mathrm{e}$ ) of about $100 \mathrm{~km}$. Hence, the radius of rainfall influence is considered as being $100 \mathrm{~km}$ for objective analysis in the present study.

\section{Results and discussion}

As stated earlier, the objective analysis is carried out at a daily scale for the southwest monsoon season of

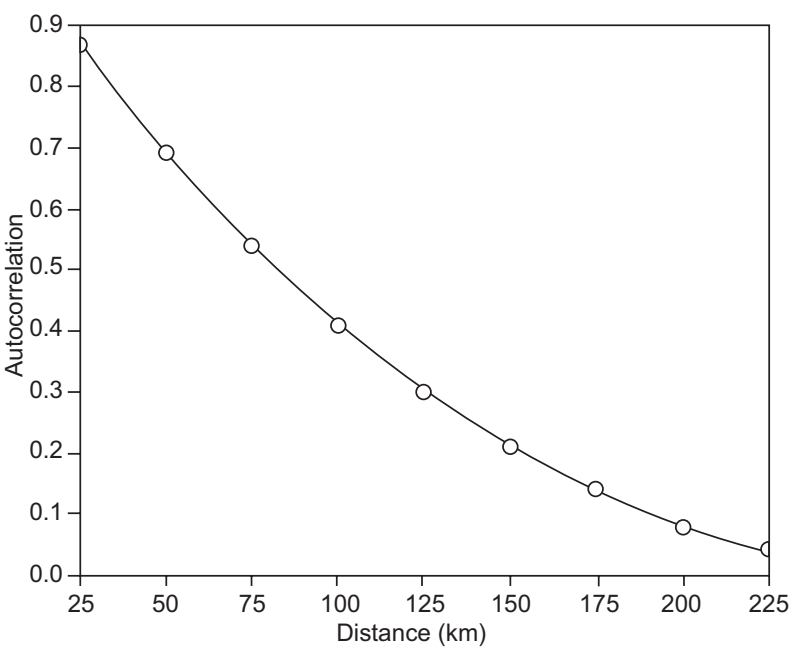

Fig. 2. Variation in the autocorrelation of daily Kalpana-1 derived IMSRA rainfall with distance over India.

2010 as a preliminary analysis. The seasonal monsoon rainfall over India was $102 \%$ of its long period average (LPA) during this year based on rain gauge data from the IMD. The monsoon onset over Kerala, which is known as the gateway of the Indian monsoon, occurred on May 31, one day earlier than its normal onset on June 1. Though the monsoon onset over Kerala took place with a very severe cyclonic storm (Phet) over the Arabian Sea, no depressions formed in the north Indian Ocean during the entire season, which was only the second time this happened after 2002 (IMD, 2010). Even without the formation of any depression throughout the season, it was the first time in the recorded history that the seasonal monsoon rainfall over India was normal. India received below normal rainfall ( $84 \%$ of LPA) only during the month of June due to a prolonged hiatus associated with the weak monsoon current in that year. The results of some case studies are presented here for brevity.

The first case study corresponds to August 6, 2010 when the monsoon was active over India due to the formation of a low-pressure area over the northwest Bay of Bengal on August 4, which moved southwestward. The spatial distributions of the Kalpana-1 derived IMSRA, objectively analyzed IMSRA (OA-IMSRA), GSMaP, TMPA near real-time (TMPA-RT), TMPA research version 7 (TMPA-V7) and GPCP rainfall are shown in Figure 3 for this day, when there was a large mesoscale convective system situated over southwest central India, and two pockets of high rainfall (more 

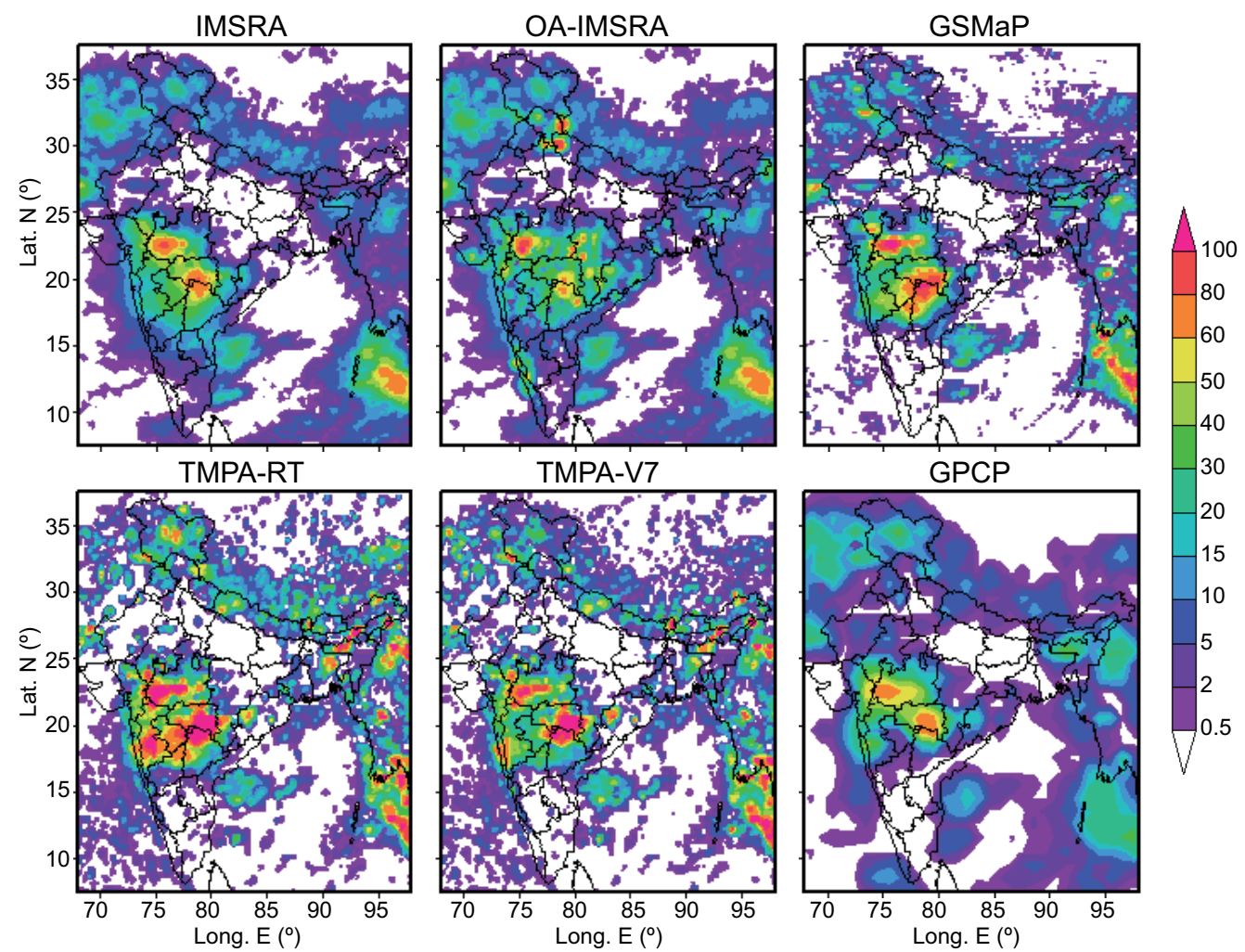

Fig. 3. Spatial distributions of daily-accumulated rainfall $(\mathrm{mm})$ over the Indian monsoon region derived from IMSRA, OA-IMSRA, GSMaP, TMPA-RT, TMPA-V7 and GPCP for August 6, 2010.

than $50 \mathrm{~mm}$ ) are observed over this region in all the rainfall products. However, the magnitude of rainfall is higher in TMPA-RT and TMPA-V7 and lower in the GPCP as compared to the other three rainfall products. The possible cause behind the underestimation of rainfall by the GPCP is its coarser resolution, which lowers the rainfall values due to area averaging. The OA-IMSRA rainfall notably shows very low or negligible values as compared to the IMSRA estimates over the area separating the two high rainfall pockets that are consistent with the TMPA-V7 rainfall products. The TMPA-V7 rainfall also shows low rainfall over this area whereas TMPA-RT shows higher rainfall. This exhibits that low rainfall is modified by the use of rain gauge data in the TMPA-V7 as well as in the OA-IMSRA estimates. Similarly, a convective system causing moderate rainfall over southeastern India is also recognized by all the rainfall products. But the areal spread of this system is larger and attached to the northwestern convective systems in the IMSRA estimate, whereas it can be seen as an independent system after the objective analysis, which is in good agreement with all four global multisatellite rainfall products. Rainfall over northern India is also slightly modified after the objective analysis and is comparable with the GSMaP estimates, though TMPA-RT and TMPA-V7 show higher rainfall than the other four values products.

The second case study corresponds to August 18, 2010 for which the IMSRA, OA-IMSRA, GSMaP, TMPA-RT, TMPA-V7 and GPCP rainfall are shown in Figure 4. There is a large convective activity over northern India and along the foothills of the Himalayas on this day. The rainfall estimated from IMSRA and OA-IMSRA is about the same and is in good agreement with the GSMaP and GPCP rainfall estimates over these regions. However, the TMPA-RT and TMPA-V7 products show slightly different rainfall features qualitatively and higher rainfall values over these regions as compared to the other rainfall products. Moreover, the IMSRA estimate shows a moderate rainfall of about $30-40 \mathrm{~mm}$ over the northern Maharashtra state and along the adjoining oceanic regions, while the OA-IMSRA rainfall estimate shows the rainfall only over the 

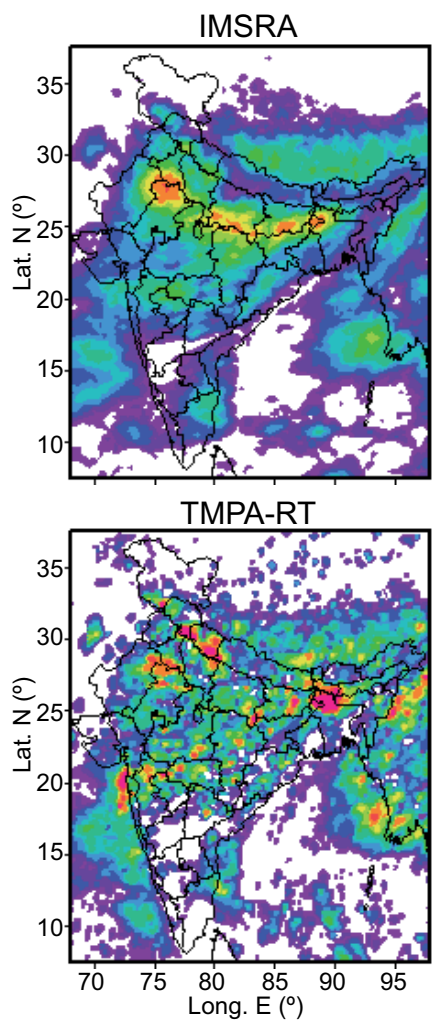
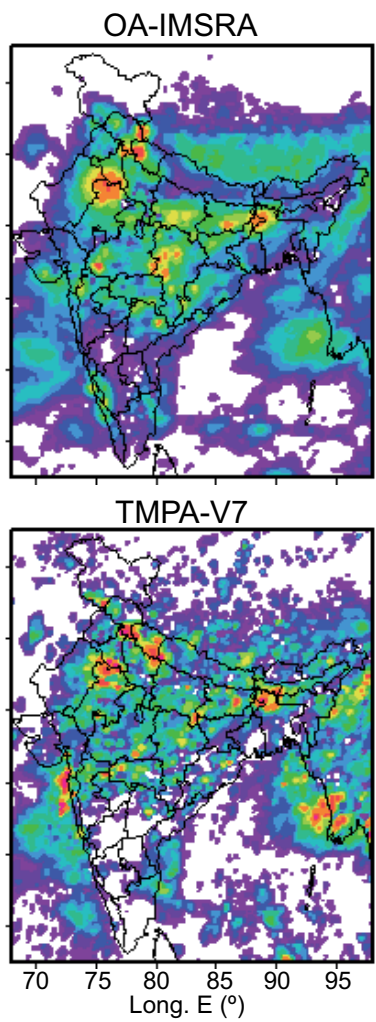

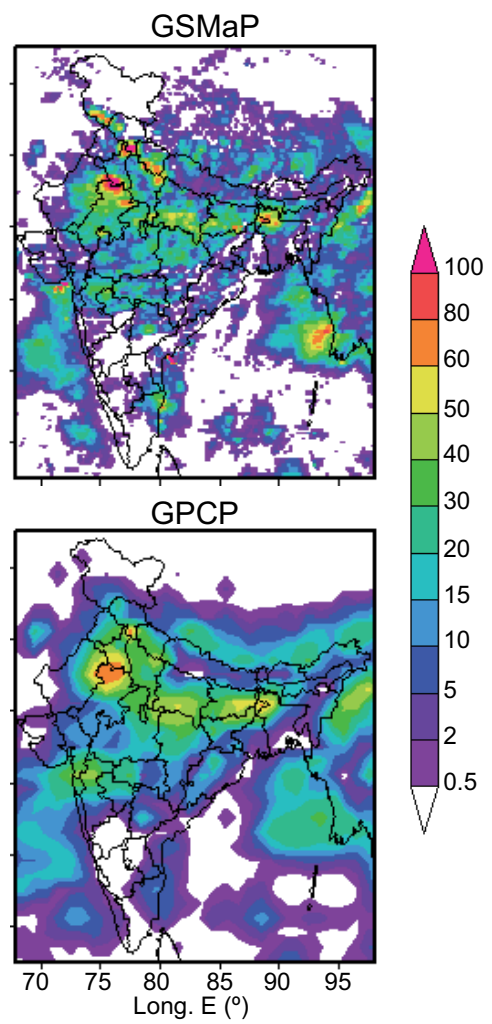

Fig. 4. Spatial distributions of daily-accumulated rainfall $(\mathrm{mm})$ over the Indian monsoon region derived from IMSRA, OA-IMSRA, GSMaP, TMPA-RT, TMPA-V7 and GPCP for August 18, 2010.

northeast part of Maharashtra state and the shape of the rainfall is also modified over Gujarat state due to the incorporation of ground-truth data from rain gauges. Rainfall over these regions from the OA-IMSRA is in better compliance with the GSMaP estimate and shows a notable improvement over the IMSRA estimate, but the geometric shape of rainfall along the west coast of India is slightly different in TMPA as compared to the other rainfall products. Moreover, TMPA show higher rainfall amounts than the other rainfall products. Similarly, over the eastern Bay of Bengal, IMSRA and GSMaP rainfall estimates are in good agreement with each other, but TMPA shows rather higher rainfall. Recently, Prakash et al. (2013) and Prakash and Gairola (2014) compared the revised version of TMPA-V7 rainfall with rain gauge data from the buoy array over the tropical oceans and reported that TMPA-V7 overestimates rainfall over the tropical Indian Ocean.

The third case study corresponds to September 7, 2010 for which the IMSRA, OA-IMSRA, GSMaP, TMPA-RT, TMPA-V7 and GPCP rainfall for this day are shown in Figure 5. Most parts of India received very good rainfall on this day. Central India and the adjoining eastern coast received higher rainfall as depicted by all the rainfall products. The IMSRA rainfall shows two pockets of rainfall (15-30 $\mathrm{mm})$ along the west coast of India, one situated over the west coast of Gujarat and another over the coastal Karnataka. However, rainfall along the west coast is noticeably modified in the OA-IMSRA estimates, which show that the spread of the rainfall is larger than in IMSRA along the west coast. Moreover, the geometrical shape of the rainfall is also modified over central India in the OA-IMSRA product with respect to IMSRA, which depicts the synoptic systems more precisely. This shows that the present scheme has potential for improved rainfall estimation over India where rainfall is substantially influenced by topography. As rainfall over India is modified in the OA-IMSRA estimates, there is no change in the rainfall amount over oceanic regions. However, the Kalpana-1 derived rainfall products show reasonable agreement with multisatellite rainfall products over the oceanic regions. Intercomparison with the four independent global multisatellite rainfall 

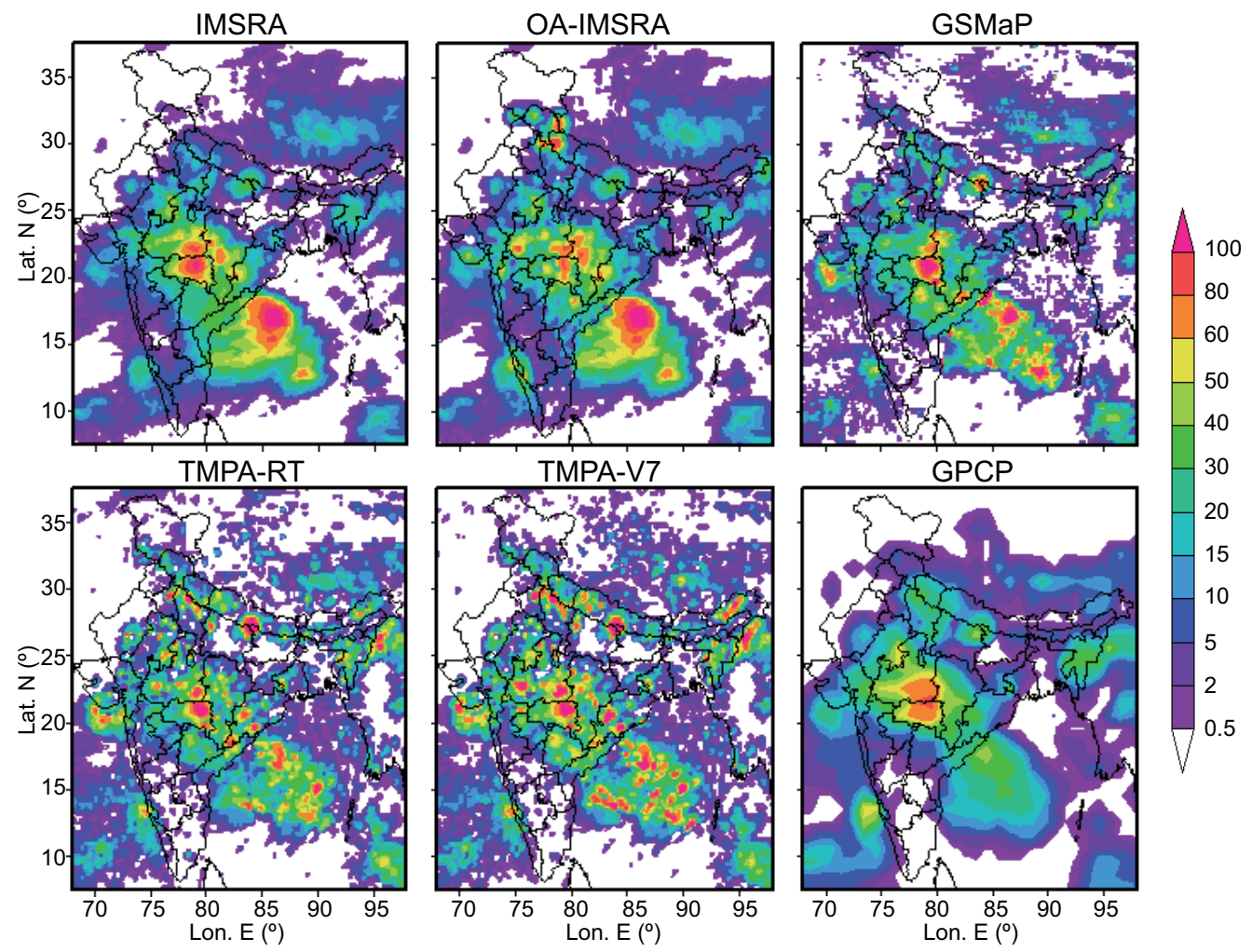

Fig. 5. Spatial distributions of daily-accumulated rainfall $(\mathrm{mm})$ over the Indian monsoon region derived from IMSRA, OA-IMSRA, GSMaP, TMPA-RT, TMPA-V7 and GPCP for September $7,2010$.

products suggests that the new analysis distinctly captures all the synoptic features of the summer monsoon as compared to the IMSRA estimates.

IMSRA and OA-IMSRA daily estimates are also quantitatively compared with GSMaP, TMPA-RT, TMPA-V7 and GPCP. For this purpose, we restricted our analysis south of $25^{\circ} \mathrm{N}$ where gauge density is fairly good. As the spatial resolution of each rainfall product is different, we performed this comparison at a common resolution of $1^{\circ}$ latitude $\times 1^{\circ}$ longitude. Table I shows the different statistical parameters, such as correlation coefficient, bias and root-mean-square error (RMSE). It can be seen that the correlation and RMSE of IMSRA are considerably improved after objective analysis. IMSRA underestimates rainfall over the southern India due to orography, which is also improved after objective analysis. The results convincingly demonstrate that the OA-IMSRA rainfall estimates perform better than the Kalpana-1 derived IMSRA rainfall estimates over India.

Furthermore, IMSRA and OA-IMSRA are validated against independent rain gauge observations (not

Table I. Statistical comparison of daily IMSRA and OA-IMSRA with GSMaP, TMPA-RT, TMPA-V7 and GPCP datasets over southern India for the southwest monsoon of 2010.

\begin{tabular}{lcccccccc}
\hline & \multicolumn{2}{c}{ Correlation coefficient } & & \multicolumn{2}{c}{ Bias (\%) } & & \multicolumn{2}{c}{ RMSE (\%) } \\
\cline { 2 - 3 } \cline { 8 - 9 } \cline { 8 - 9 } & IMSRA & OA-IMSRA & & IMSRA & OA-IMSRA & & IMSRA & OA-IMSRA \\
\hline GSMaP & 0.70 & 0.83 & & 9.12 & 22.32 & & 119.08 & 80.70 \\
TMPA-RT & 0.57 & 0.74 & & -14.72 & 1.94 & & 154.85 & 103.69 \\
TMPA-V7 & 0.65 & 0.81 & & -8.88 & 6.93 & & 132.38 & 84.28 \\
GPCP & 0.56 & 0.71 & & -2.67 & 12.24 & & 144.24 & 102.65 \\
\hline
\end{tabular}


used for the objective analysis). Figure 6 shows the scatter plots of daily IMSRA and OA-IMSRA rainfall estimates with rain gauge observations over southern India for the monsoon season of 2010. IMSRA shows a correlation coefficient of 0.54 with the gauge dataset, which is increased to 0.70 after objective analysis. Similar improvement in bias and RMSE is also seen, which confirms the positive impact of objective analysis. This study has shown sufficiently promising results and suggests that this method has a potential for more accurate rainfall estimation over the Indian monsoon region at higher spatial resolution.

\section{Conclusions}

This study demonstrates the potential of objective analysis for improved rainfall estimation over India from surface rain gauge data and Kalpana-1 satellite derived indigenous IMSRA estimates at a $0.25^{\circ}$ latitude $\times 0.25^{\circ}$ longitude spatial resolution The successive correction method, one of the most widely spread techniques, was used for the objective analysis, which combines the relative advantages of rain gauge and satellite-based rainfall data. The radius of rainfall influence was determined by the spatial autocorrelation analysis and was found to be $100 \mathrm{~km}$. This objective analysis scheme was applied to several cases of rainfall over India at a daily scale during the southwest monsoon season of 2010 and intercompared with four independent global multisatellite rainfall products, namely GSMaP,
TMPA-RT, TMPA-V7 and GPCP. The analyzed rainfall estimates agreed well with the multisatellite estimates and showed an improvement over IMSRA. Moreover, the analyzed rainfall product was found to be very realistic and capable of capturing the orographic rainfall along the west coast of India noticeably better than the IMSRA estimates. Comparison of OA-IMSRA with independent rain gauge observations showed that RMSE is reduced by about $20 \%$ as compared to IMSRA after objective analysis over southern India. However, the impact of objective analysis was negligible over the northern parts of India due to lack of rain gauges. As the rain gauge data of India was used for the analysis, no significant difference from IMSRA was noticed in the analyzed rainfall estimates over the oceanic regions. The results suggest that the present approach performs better than satellite-based rainfall estimates alone and has a potential for the monitoring and analysis of monsoon rainfall at a finer scale. Furthermore, the augmentation of rain gauges, especially over the northern part of India, would essentially improve the rainfall estimates over this region along with the INSAT-3D and Global Precipitation Mission satellites.

\section{Acknowledgments}

The authors would like to thank the Director of the Space Applications Centre and the Deputy Director of the EPSA, SAC for their kind support. They also
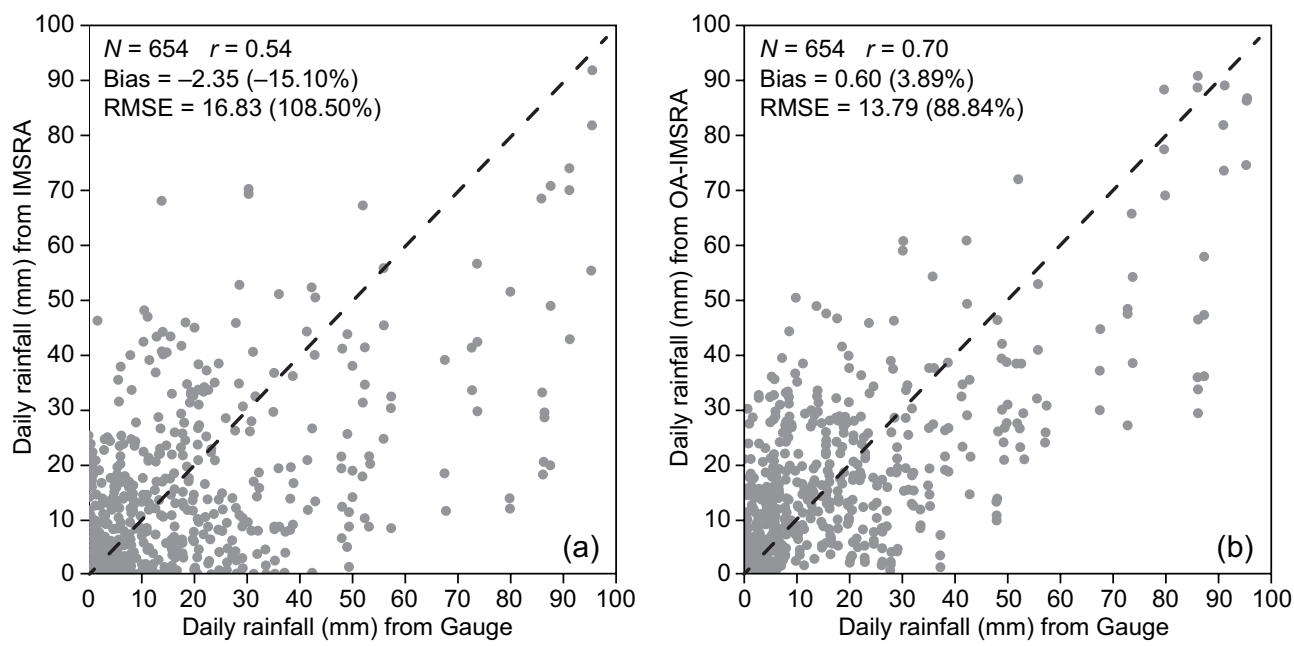

Fig. 6. Scatter plots of daily rainfall from (a) IMSRA and rain gauge data, and (b) OA-IMSRA and rain gauge data over southern India for the monsoon season of 2010. Dashed lines show a 1:1 line; $N$ denotes the number of matches, and $r$ denotes correlation coefficient. 
thank two anonymous reviewers for constructive comments. Our appreciation goes also to Dr. V. Sathiyamoorthy and D. N. Piyush for their help in objective and autocorrelation analysis, respectively. The Kalpana-1 satellite data and rain gauge data from the MOSDAC, GSMaP rainfall data from the JAXA, TMPA rainfall data from the TOVAS, and GPCP data from the website at http://precip.gsfc.nasa.gov are also thankfully acknowledged.

\section{References}

Adler R. F., G. J. Huffman, A. Chang, R. Ferraro, P. P. Xie, J. Janowiak, B. Rudolf, U. Schneider, S. Curtis, D. Bolvin, A. Gruber, J. Susskind, P. Arkin and E. Nelkin, 2003. The version-2 Global Precipitation Climatology Project (GPCP) monthly precipitation analysis (1979-present). J. Hydrometeorol. 4, 1147-1167.

Aonashi K., J. Awaka, M. Hirose, T. Kozu, T. Kubota, G. Liu, S. Shige, S. Kida, S. Seto, N. Takahashi and Y. N. Takayabu, 2009. GSMaP passive microwave precipitation retrieval algorithm: Algorithm description and validation. J. Meteorol. Soc. Jpn. 87A, 119-136, doi:10.2151/jmsj.87A.119.

Arkin P. A. and B. N. Meisner, 1987. The relationship between large-scale convective rainfall and cold cloud over the western hemisphere during 1982-84. Mon. Weather Rev. 115, 51-74.

Cressman G. P., 1959. An operational objective analysis system. Mon. Weather Rev. 87, 367-374.

Das S. K., S. K. Deb, C. M. Kishtawal and P. K. Pal, 2013. Seasonal prediction of Indian summer monsoon: Sensitivity to persistent SST. J. Earth Syst. Sci. 122, 1183-1193, doi:10.1007/s12040-013-0351-6.

Gairola R. M. and T. N. Krishnamurti, 1992. Rain rates based on SSM/I, OLR and rain gauge data sets. Meteorol. Atmos. Phys. 50, 165-174.

Gairola R. M., A. Mishra, S. Prakash and C. Mahesh, 2010a. Rainfall estimation from Kalpana-1 IR data using GPI approach and initial validations using AWS observations. Scientific Report SAC/EPSA/AOSG/ INSAT/SR-36/2010.

Gairola R. M., A. Mishra, S. Prakash and C. Mahesh, 2010b. Development of INSAT Multi-Spectral Rainfall Algorithm (IMSRA) for monitoring rainfall events over India using KALPANA-IR and TRMM-precipitation radar observations. Scientific Report SAC/EPSA/ AOSG/INSAT/SR-39/2010.

Gairola R. M., S. Prakash and C. Mahesh, 2012. Synergistic use of Kalpana-1 and rain gauge data for rainfall estimation: A case study over Gujarat. Workshop on Meteorological Satellite Kalpana: A decade of Service to the Nation. Ahmedabad, India, October.

Huffman G. J., R. F. Adler, M. Morrissey, D. T. Bolvin, S. Curtis, R. Joyce, B. McGavock and J. Susskind, 2001. Global precipitation at one-degree daily resolution from multisatellite observations. J. Hydrometeorol. 2, 36-50.

Huffman G. J., R. F. Adler, D. T. Bolvin, G. Gu, E. J. Nelkin, K. P. Bowman, Y. Hong, E. F. Stocker and D. B. Wolff, 2007. The TRMM Multisatellite Precipitation Analysis (TMPA): Quasi-global, multiyear, combined-sensor precipitation estimates at fine scales. J. Hydrometeorol. 8, 38-55, doi:10.1175/JHM560.1.

Huffman G. J., R. F. Adler, D. T. Bolvin and E. J. Nelkin, 2010. The TRMM Multi-Satellite Precipitation Analysis (TMPA), in: Satellite applications for surface hydrology (F. Hossain and M. Gebremichael, Eds.). Springer Verlag, 327 pp.

IMD, 2010. Southwest monsoon-2010: End of season report. India Meteorological Department, Ministry of Earth Sciences, New Delhi, pp. 1-14.

Kaila V. K., A. S. Kiran Kumar, T. K. Sundarmurthy, S. Ramkrishnan, M. V. S. Prasad and P. S. Desai, 2002. METSAT- a unique mission for weather and climate. Curr. Sci. 83, 1081-1088.

Krishnamurti T. N., A. K. Mishra, A. Simon and A. Yatagai, 2009. Use of a dense rain-gauge network over India for improving blended TRMM products and downscaled weather models. J. Meteorol. Soc. Jpn. 87A, 393-414, doi:10.2151/jmsj.87A.393.

Kubota T., S. Shige, H. Hashizume, A. Aonashi, N. Takahashi, S. Seto, M. Hirose, Y. N. Takayabu, T. Ushio, K. Nakagawa, K. Iwanami, M. Kachi and K. Okamoto, 2007. Global precipitation map using satellite-borne microwave radiometers by the GSMaP project: Production and validation. IEEE T. Geosci. Remote 45, 2259-2275.

Mahesh C., S. Prakash, R. M. Gairola, S. Shah and P. K. Pal, 2014. Meteorological sub-divisional scale rainfall monitoring using Kalpana-1 VHRR measurements. Geogr. Res. 52, 328-336, doi:10.1111/17455871.12068 .

Mishra A., R. M. Gairola, A. K. Varma and V. K. Agarwal, 2009. Study of intense rainfall events over India using Kalpana-IR and TRMM-precipitation radar observations. Curr. Sci. 97, 689-695.

Mishra A., R. M. Gairola, A. K. Varma and V. K. Agarwal, 2010. Remote sensing of precipitation over Indian land 
and oceanic regions by synergistic use of multi-satellite sensors. J. Geophys. Res.115, D08106, doi:10.1029/ 2009JD012157.

Mitra A. K., M. Das Gupta, S. V. Singh and T. N. Krishnamurti, 2003. Daily rainfall for the Indian monsoon region from merged satellite and rain gauge values: Large-scale analysis from real-time data. J. Hydrometeorol. 4, 769-781.

Mitra A. K., A. K. Bohra, M. N. Rajeevan and T. N. Krishnamurti, 2009. Daily Indian precipitation analysis formed from a merge of rain-gauge data with the TRMM TMPA satellite-derived rainfall estimates. $J$. Meteorol. Soc. Jpn. 87A, 265-279.

Prakash S., C. Mahesh, A. Mishra, R. M. Gairola, A. K. Varma and P. K. Pal, 2009. Combined use of microwave and IR data for the study of Indian monsoon rainfall-2009. ISPRS Archives XXXVIII-8/W3 Workshop Proceedings: Impact of Climate Change on Agriculture. Ahmedabad, India, December, pp. 227-230.

Prakash S., C. Mahesh, R. M. Gairola and P. K. Pal, 2010. Estimation of Indian summer monsoon rainfall using Kalpana-1 VHRR data and its validation using rain gauge and GPCP data. Meteorol. Atmos. Phys. 110, 45-57, doi:10.1007/s00703-010-0106-8.

Prakash S., C. Mahesh and R. M. Gairola, 2011. Largescale precipitation estimation using Kalpana-1 IR measurements and its validation using GPCP and GPCC data. Theor. Appl. Climatol. 106, 283-293, doi:10.1007/ s00704-011-0435-7.

Prakash S., C. Mahesh, R. M. Gairola and B. Buyantogtokh, 2012. A feasibility of six-hourly rainfall forecast over central India using model output and remote sensing data. Int. J. Hydrol. Sci. Technol. 2, 138-152. doi:10.1504/IJHST.12.47409.
Prakash S., C. Mahesh and R. M. Gairola, 2013. Comparison of TRMM Multisatellite Precipitation Analysis (TMPA)-3B43 version 6 and 7 products with rain gauge data from ocean buoys. Remote Sens. Lett. 4, 677-685, doi:10.1080/2150704X.2013.783248.

Prakash S. and R. M. Gairola, 2013. Estimation of sea surface salinity in the tropical Indian Ocean by synergistic use of SMOS and RAMA buoy data. Meth. Oceanogr. 8, 33-40, doi:10.1016/j.mio.2014.06.003.

Prakash S. and R. M. Gairola, 2014. Validation of TRMM3B42 precipitation product over the tropical Indian Ocean using rain gauge data from the RAMA buoy array. Theor. Appl. Climatol. 115, 451-460, doi:10.1007/ s00704-013-0903-3.

Prakash S., V. Sathiyamoorthy, C. Mahesh and R. M. Gairola, 2014. An evaluation of high-resolution multisatellite rainfall products over the Indian monsoon region. Int. J. Remote Sens. 35, 3018-3035, doi:10.10 80/01431161.2014.894661.

Roy Bhowmik S. K., D. Joardar and A. K. Das, 2005. Radius of rainfall influence over Indian monsoon region. Geofizika 22, 131-141.

Roy Bhowmik S. K. and A. K. Das, 2007. Rainfall analysis for Indian monsoon region using the merged rain gauge observations and satellite estimates: Evaluation of monsoon rainfall features. J. Earth Syst. Sci. 116(3), 187-198.

Sen Roy S., S. B. Saha, H. Fatima, S. K. Roy Bhowmik and P. K. Kundu, 2012. Evaluation of short-period rainfall estimates from Kalpana-1 satellite using MET software. J. Earth Syst. Sci. 121, 1113-1123.

Thiebaux H. J and M. A. Pedder, 1987. Spatial Objective analysis - with applications in atmospheric science. Academic Press, London, 299 pp. 